\title{
Validation of exhaled volatile organic compounds analysis using electronic nose as index of COPD severity
}

This article was published in the following Dove Press journal: International Journal of COPD

\author{
Panaiotis Finamore \\ Claudio Pedone' \\ Simone Scarlata' \\ Alessandra Di Paolo' \\ Simone Grasso ${ }^{2}$ \\ Marco Santonico ${ }^{2}$ \\ Giorgio Pennazza ${ }^{2}$ \\ Raffaele Antonelli Incalzi' \\ 'Unit of Geriatrics, Campus Bio- \\ Medico di Roma University, Rome, \\ Italy; ${ }^{2}$ Unit of Electronics for Sensor \\ Systems, Campus Bio-Medico di Roma \\ University, Rome, Italy
}

Correspondence: Panaiotis Finamore Unit of Geriatrics, Campus Bio-Medico di Roma University, Via Alvaro del Portillo, 200, 00128 Rome, Italy

Tel +3906225411336

Fax +390622541456

Email p.finamore@unicampus.it

\begin{abstract}
Aim: Six-minute walking test distance (6MWD) and body mass index, obstruction, dyspnea and exercise (BODE) index are measures of functional status in COPD patients, but require space, time and patient's compliance. Exhaled volatile organic compounds (VOCs) analysis via electronic nose is a quick and easy method that has already been used to discriminate COPD phenotypes. The aim of this study is to evaluate whether VOCs analysis can predict functional status and its variation over time in COPD patients.
\end{abstract}

Methods: A monocentric prospective study with 1 year of follow-up was carried out. All patients underwent pulmonary function tests, arterial gas analysis, bioimpedance analysis, 6-minute walking test, and VOCs collection. Exhaled breath was collected with Pneumopipe ${ }^{\circledR}$ and analyzed using BIONOTE electronic nose. Outcomes prediction was performed by $k$-fold cross-validated partial least square discriminant analysis: accuracy, sensitivity and specificity as well as Cohen's kappa for agreement were calculated.

Results: We enrolled 63 patients, 60.3\% men, with a mean age of 71 (SD: 8) years, median BODE index of 1 (interquartile range: 0-3) and mean 6MWD normalized by squared height (n6MWD) of 133.5 (SD: 42) $\mathrm{m} / \mathrm{m}^{2}$. The BIONOTE predicted baseline BODE score (dichotomized as BODE score $<3$ or $\geq 3$ ) with an accuracy of $86 \%$ and quartiles of n6MWD with an accuracy of $79 \%$. n6MWD decline more than the median value after 1 year was predicted with an accuracy of $86 \%$ by BIONOTE, $52 \%$ by Global Initiative for Chronic Obstructive Lung Disease (GOLD) class and 78\% by combined BIONOTE and GOLD class.

Conclusion: Exhaled VOCs analysis identifies classes of BODE and n6MWD quartiles, and outperforms GOLD classification in predicting n6MWD variation.

Keywords: volatile organic compounds, electronic nose, 6-minute walking test, COPD, functional status, BODE index

\section{Introduction}

Since 2010, COPD has become the third leading cause of death, accounting for 2.8 million deaths worldwide. ${ }^{1}$ Identifying patients with a steeper progression toward disability and death is warranted to implement monitoring and therapy.

Different systems have been proposed to categorize COPD severity and rate of functional status decline. The Global Initiative for Chronic Obstructive Lung Disease (GOLD) proposed a severity classification based on reduction of forced expiratory volume in the first second $\left(\mathrm{FEV}_{1}\right)$ expressed as percent of predicted value, ${ }^{2}$ and then updated the risk stratification adding clinical parameters ${ }^{3}$ to take into account the burden of symptoms. Nonetheless, neither the first nor the second GOLD classification has demonstrated sufficient discrimination ability in stratifying COPD functional 
impairment severity. ${ }^{4-6}$ Compared with GOLD classifications, the 6-minute walking test (6MWT) has a better association with clinical outcomes, such as mortality, ${ }^{7-9}$ either alone or when used together with other variables in the body mass index (BMI), obstruction, dyspnea and exercise (BODE) index. ${ }^{10}$ The 6MWT should be performed in a corridor of at least $30 \mathrm{~m}$ length, which may not be available in some settings, and requires patient's compliance to obtain reliable measures; ${ }^{11}$ therefore, new approaches that are less demanding in terms of space and patient's compliance may be helpful to rate functional impairment.

Exhaled volatile organic compounds (VOCs) analysis through electronic nose is a promising approach in the study of lung disease. This technique provides a "fingerprint" of the exhaled breath (dubbed "breathprint"), obtained by interaction occurring between VOCs and a sensor array, which has been shown to discriminate COPD patients from healthy controls, patients with asthma ${ }^{12}$ and patients with heart failure, ${ }^{13}$ and seems promising in COPD phenotyping. ${ }^{14,15}$ Considering that factors affecting COPD patients' functional status (ie, systemic inflammation and hypoxemia ${ }^{16}$ ) are also modifiers of VOCs production, ${ }^{17}$ this proof-of-concept study aims to evaluate whether exhaled fingerprint predicts the functional status in COPD patients and whether and to which extent it might improve the GOLD discrimination ability. Therefore, the objectives of this study are 1) to evaluate whether VOCs analysis of COPD patients using electronic nose discriminates quartiles of 6-minute walking test distance normalized by squared height (n6MWD) and classes of BODE index, also in comparison with GOLD classification; and 2) to evaluate whether VOCs analysis predicts changes in the n6MWD after 1 year.

\section{Patients and methods}

\section{Study design}

This was a 1-year monocentric and observational prospective study carried out at "Campus Bio-Medico" Hospital in Rome (Italy). The data used in the present study were collected from September 2015 to September 2016. The study protocol was approved by the Ethical Committee of Campus Bio-Medico di Roma University (protocol number: 30/15 PAR CMB). All the study participants provided written informed consent.

Inclusion criteria were diagnosis of COPD defined as the evidence of persistent airflow limitation at spirometry, which is defined as $\mathrm{FEV}_{1} /$ forced vital capacity $<0.7$ after administration of $400 \mu \mathrm{g}$ of salbutamol, ${ }^{18}$ and the absence of exacerbations and of changes in pharmacological therapy in the previous 3 months.
Exclusion criteria were inability to perform an acceptable spirometry following the American Thoracic Society and the European Respiratory Society (ATS/ERS) guidelines, ${ }^{18}$ diagnosis of pulmonary cancer or pulmonary fibrosis, severe cognitive impairment as indicated by a mini-mental state examination (MMSE) score $<10$, inability to perform the 6MWT due to mobility limitations, heart failure of New York Heart Association (NYHA) class III or IV and, finally, refusal to provide informed consent.

\section{Clinical assessment}

The study involved 63 stable COPD patients consecutively enrolled. Demographic and physiological characteristics, level of dyspnea (determined using the modified Medical Research Council [mMRC] dyspnea scale), number of exacerbations, pulmonary function tests (post-bronchodilator spirometry and lung volumes), 6MWT, arterial gas and bioimpedance analysis, multidimensional assessment results and comorbidities, which were identified based on patients' documentation, medical history, physical examination and routine blood analysis, were recorded during the visit, both at baseline and after 1 year.

Forced expiratory volumes were measured using a watersealed bell spirometer (Biomedin, Padua, Italy) following the acceptability and reproducibility criteria proposed by the ATS/ERS. ${ }^{18}$ Total lung capacity and residual volume were determined using the Helium-rebreathing technique. ${ }^{19}$ Multidimensional assessment was made up by the following: functional ability, estimated using the Katz activities of daily living and the Lawton and Brody instrumental activities of daily living, ${ }^{20,21}$ cognitive function, evaluated using MMSE; ${ }^{22}$ and depressive symptoms, estimated using 15-item Italian version of the Geriatric Depression Scale. ${ }^{23}$

\section{Collection and analysis of VOCs}

Exhaled breath was collected only at baseline, in the morning, early after awakening, with patients fasting, smoking free and having refrained from medication consumption for at least 8 hours. All patients performed breath collection in the same room and with the same procedure.

Patients were asked to breath tidally for 3 minutes into a mouthpiece connected with Pneumopipe ${ }^{\circledR}$ (European patent no 12425057.2; Rome, Italy), a device ensuring in a fixed time a noninvasive collection of mixed expiratory sample into an adsorbent Tenax GR cartridge (Supelco; SigmaAldrich, St Louis, MO, USA) ${ }^{24}$ Cartridge content was then thermally desorped into the sensor chamber of our electronic nose, named BIONOTE, by a device uniformly heating the 
cartridge at four different temperatures: $50^{\circ} \mathrm{C}, 100^{\circ} \mathrm{C}, 150^{\circ} \mathrm{C}$ and $200^{\circ} \mathrm{C}$. BIONOTE is a seven quartz microbalance (QMB) sensor array. Sensors are covered with anthocyanins extracted from three different plant tissues and used as chemical interactive materials. Desorbed VOCs interact with the chemicals covering the sensor's surface via weak bonding forces, and interaction results in seven frequency shifts of each of the QMB with respect to their typical resonance frequency for each desorption temperature, so we finally achieve 28 responses (seven QMB tested per four different temperatures) in the analysis. This technology has been validated, and its performance has been evaluated in gases and vapors calibration experiments. ${ }^{25}$

\section{MWT and BODE index}

Six-minute walking test is a clinical exercise test measuring the distance that a patient can quickly walk in a period of 6 minutes. It provides global information on the organs contributing to exercise capacity, but it is not able to disentangle the contribution of each system. The test was performed in the morning, after exhaled breath collection, according to the ATS guidelines. ${ }^{11}$ In summary, participants were asked to walk in a flat, straight and $30 \mathrm{~m}$ hallway for 6 minutes as quickly as they could, under the supervision of a trained technician. $\mathrm{SpO}_{2}$ was measured throughout the test using a pulse oximeter with a finger probe. Dyspnea was rated at the end of the test using Borg scale. The 6-minute walking test distance (6MWD), basal $\mathrm{SpO}_{2}$, nadir $\mathrm{SpO}_{2}$ and Borg score were recorded. Since anthropometric features affect $6 \mathrm{MWD},{ }^{26-28}$ we used n6MWD to avoid their impact on the treaded distance as has been suggested for $\mathrm{FEV}_{1} \cdot{ }^{29}$

The BODE index is a scoring system used to predict allcause mortality in patients with stable COPD, and it is based on four variables: $\mathrm{BMI}, \mathrm{FEV}_{1}$ (percent of predicted), dyspnea rated using COPD Assessment Tool or mMRC and 6MWD. Total score ranges from 0 to 10 ; the higher is the score, the lower is the estimated survival. A BODE score higher than 3 is associated with a poorer prognosis. ${ }^{10}$

\section{Statistical analysis}

We reported the characteristics of our sample using descriptive statistics. Participants were divided into quartiles of n6MWD, which were compared using analysis of variance (ANOVA) and Kruskal-Wallis test for normally and nonnormally distributed continuous variables, respectively, and $\chi^{2}$ test or Fisher's exact test for categorical variables, as appropriate.
Partial least square discriminant analysis (PLS-DA), applied on patients' BIONOTE sensor responses, previously centered and scaled, was used to predict the quartiles of n6MWD taking into account the individual's anthropometric features affecting 6MWD. The same method was used to predict BODE score, classified as "good prognosis" (BODE score $<3$ ) and "poor prognosis" (BODE score $\geq 3$ ), ${ }^{30}$ which represented the "gold standard" for this analysis. To avoid overfitting, we used a "repeated $k$-fold cross validation". The overall effectiveness of classification was expressed as diagnostic accuracy, which is the proportion of subjects correctly classified by the PLS-DA among all subjects, sensitivity and specificity. Furthermore, we measured the agreement between the model based on BIONOTE responses and reference n6MWD quartiles and BODE classes using Cohen's kappa. ${ }^{31}$ Then, we compared the quartiles of n6MWD $\left(\mathrm{m} / \mathrm{m}^{2}\right)$ with 2014 GOLD classes, measuring overall effectiveness and agreement with the same procedure as done before, and analyzed the distribution of classes of BODE score across GOLD classes.

Finally, we evaluated whether VOC analysis could predict changes in the n6MWD over time. For this analysis, the "gold standard" was represented by the variation of walked distance which was dichotomized using the median $\left(-7.9 \mathrm{~m} / \mathrm{m}^{2}\right)$ as the cut-off value into "stable/improved" or "worsened". For this analysis, we compared predictions based on VOC only with predictions made on GOLD classes only and on the combination of the previous two parameters. Accuracy, sensitivity and specificity, as well as Cohen's kappa were calculated.

All the analyses were performed using $\mathrm{R}$ version 3.3.0 (The R Foundation for Statistical Computing, Vienna, Austria).

\section{Results}

The characteristics of the participants at baseline are summarized in Table 1. Mean age of the participants was 71 (SD: 8) years, 38 (60.3\%) were men, mean BMI was 28.1 (SD: 5.9) kg/m², mean $\mathrm{FEV}_{1}$ \% was 69.6 (SD: 22.3), mean pack/year was 35.1 (SD: 26.6) and 25 (39.7\%) were current smokers, while $32(50.8 \%)$ were former smokers. Of the 63 participants, 35 (55.6\%) were in GOLD A class, nine (14.5\%) in GOLD B class, eight (12.4\%) in GOLD C class and $11(17.5 \%)$ in GOLD D class. Mean 6MWD was 366.8 (SD: 111.5) $\mathrm{m}$, and mean n6MWD was 133.5 (SD: 42) $\mathrm{m} / \mathrm{m}^{2}$. Patients in the first quartile of n6MWD treaded from $166 \mathrm{~m} / \mathrm{m}^{2}$ to $215 \mathrm{~m} / \mathrm{m}^{2}$, those in the second from $146 \mathrm{~m} / \mathrm{m}^{2}$ to $165 \mathrm{~m} / \mathrm{m}^{2}$, those in the third from $112 \mathrm{~m} / \mathrm{m}^{2}$ to $145 \mathrm{~m} / \mathrm{m}^{2}$ and those in the fourth quartile from $22 \mathrm{~m} / \mathrm{m}^{2}$ to 
Table I Baseline characteristics of the population $(\mathrm{N}=63)$ and quartiles of $6 \mathrm{MWD}$ normalized by squared height $\left(\mathrm{m} / \mathrm{m}^{2}\right)$

\begin{tabular}{|c|c|c|c|c|c|c|}
\hline Characteristics & $\begin{array}{l}\text { Population, } \\
\mathbf{N}=63\end{array}$ & $\begin{array}{l}22-111 \mathrm{~m} / \mathrm{m}^{2} \\
\mathrm{n}=16\end{array}$ & $\begin{array}{l}I \mid 2-145 \mathrm{~m} / \mathrm{m}^{2} \\
\mathrm{n}=16\end{array}$ & $\begin{array}{l}146-165 \mathrm{~m} / \mathrm{m}^{2} \\
\mathrm{n}=16\end{array}$ & $\begin{array}{l}166-215 \mathrm{~m} / \mathrm{m}^{2} \\
\mathrm{n}=15\end{array}$ & $P$-value \\
\hline Age & $71(8)$ & $73.9(6.9)$ & $71.6(8.6)$ & $70.2(6.8)$ & $68.2(8.5)$ & 0.22 \\
\hline $\operatorname{Sex}(M)$ & $38(60.3)$ & $12(75)$ & II (69) & $9(56)$ & $6(40)$ & 0.21 \\
\hline Body mass index $\left(\mathrm{kg} / \mathrm{m}^{2}\right)$ & $28.1(5.9)$ & $30.2(7.1)$ & $31.1(6.3)$ & $25.2(2.8)$ & $25.8(4.5)$ & 0.004 \\
\hline \multicolumn{7}{|l|}{$\mathrm{mMRC}$} \\
\hline $0-1$ & $43(68)$ & $6(37)$ & $13(8 \mid)$ & $12(75)$ & $12(80)$ & 0.01 \\
\hline$\geq 2$ & $20(32)$ & $10(63)$ & $3(19)$ & $4(25)$ & $3(20)$ & 0.01 \\
\hline \multicolumn{7}{|l|}{ Exacerbation/year } \\
\hline $0-1$ & $48(76)$ & $13(81)$ & $10(63)$ & $12(75)$ & $13(87)$ & 0.46 \\
\hline$\geq 2$ & $15(24)$ & $3(19)^{\prime}$ & $6(37)^{\prime}$ & $4(25)^{\prime}$ & $2(13)^{\prime}$ & 0.46 \\
\hline \multicolumn{7}{|l|}{ Smoking habit } \\
\hline Current smokers & $25(39.7)$ & $5(3 I)$ & $7(44)$ & $8(50)$ & $5(33)$ & 0.6 \\
\hline Former smokers & $32(50.8)$ & $9(56)$ & $9(56)$ & $7(43)$ & $7(47)$ & 0.6 \\
\hline Pack/year & $35.1(26.6)$ & $41.2(30)$ & $40.9(26.7)$ & $26.4(18)$ & $31.7(28)$ & 0.32 \\
\hline \multicolumn{7}{|l|}{ GOLD classification 2014} \\
\hline GOLD A & $35(55.6)$ & $4(25)$ & $9(56)$ & II (69) & II (73) & 0.01 \\
\hline GOLD B & $9(14.5)$ & $5(3 I)$ & $0(0)$ & $2(13)$ & $2(13)$ & 0.01 \\
\hline GOLD C & $8(12.4)$ & I (6) & $3(19)$ & $2(13)$ & $2(13)$ & 0.01 \\
\hline GOLD D & II (I7.5) & $6(38)$ & $4(25)$ & I (6) & $0(0)$ & 0.01 \\
\hline BODE index & $I(0-3)$ & $3(2-5)$ & I $(0-3)$ & $0(0-1)$ & $0(0-1)$ & $<0.00 \mathrm{I}$ \\
\hline \multicolumn{7}{|l|}{ Spirometry } \\
\hline $\mathrm{FEV}_{1} / \mathrm{FVC}$ & $63.2(9.6)$ & $61.5(12.6)$ & $61.5(9.2)$ & $65(8.4)$ & $65(7.3)$ & 0.55 \\
\hline $\mathrm{FEV}_{1}\left(\mathrm{~cm}^{3}\right)$ & $1.7(0.7)$ & $1.5(0.6)$ & $1.7(0.5)$ & $2(1)$ & $1.8(0.5)$ & 0.2 \\
\hline $\mathrm{FEV}, \%$ & $69.6(22.3)$ & $57.9(22)$ & $64.6(20.7)$ & $78.6(27)$ & $77.7(9.4)$ & 0.02 \\
\hline $\mathrm{FVC}\left(\mathrm{cm}^{3}\right)$ & $2.8(\mathrm{I})$ & $2.5(I . I)$ & $2.7(0.6)$ & $3.1(1.4)$ & $2.8(0.9)$ & 0.45 \\
\hline FVC\% & $86.3(22.6)$ & $72.4(21.5)$ & $82.3(23.1)$ & $94.7(25.2)$ & $96.3(9.8)$ & 0.006 \\
\hline $\operatorname{TLC}\left(\mathrm{cm}^{3}\right)$ & $5.9(1.6)$ & $5.9(1.5)$ & $5.8(1.2)$ & $6.6(2.1)$ & $5.3(1.4)$ & 0.17 \\
\hline TLC\% & $100.9(24.7)$ & $97.2(40.7)$ & $92.4(13.7)$ & 114.1 (I5) & $100.2(17)$ & 0.1 \\
\hline $\mathrm{RV} / \mathrm{TLC}\left(\mathrm{cm}^{3}\right)$ & $52.5(I I .5)$ & $57.5(10.9)$ & $49.4(15.4)$ & $52(9.5)$ & $51.5(8.5)$ & 0.29 \\
\hline RV/TLC\% & $126.5(26.5)$ & | $32.4(29.8)$ & $124.7(3 \mathrm{I})$ & $125.4(22)$ & $123.9(23)$ & 0.84 \\
\hline \multicolumn{7}{|l|}{ Arterial gas analysis } \\
\hline $\mathrm{pH}$ & $7.4 I(0.03)$ & $7.4 I(0.02)$ & $7.42(0.03)$ & $7.42(0.03)$ & $7.42(0.04)$ & 0.13 \\
\hline $\mathrm{pO}_{2}(\mathrm{mmHg})$ & $77.6(10.7)$ & $74.4(11.4)$ & $74.5(9.9)$ & $77.8(11)$ & $84(8.5)$ & 0.04 \\
\hline $\mathrm{PCO}_{2}(\mathrm{mmHg})$ & $39.3(5)$ & $4 \mid(6.3)$ & $40.2(3)$ & $39.2(5.5)$ & $36.5(4)$ & 0.08 \\
\hline $\mathrm{SO}_{2}$ & $95.1(1.7)$ & $94.5(1.7)$ & $94.7(1.7)$ & $95.2(1.8)$ & $96.1(0.9)$ & 0.04 \\
\hline \multicolumn{7}{|l|}{ Multidimensional assessment } \\
\hline CIRS comorbidity index & $0(0-1)$ & $0(0-1)$ & I (0-2) & $0(0-1)$ & $0(0-1)$ & 0.2 \\
\hline CIRS severity index & $0.7(0.4)$ & $0.7(0.4)$ & $0.8(0.3)$ & $0.5(0.2)$ & $0.7(0.4)$ & 0.16 \\
\hline MMSE & $27.9(2.9)$ & $27.5(2.4)$ & $28.9(1.7)$ & $27.4(3.5)$ & $27.7(3.7)$ & 0.4 \\
\hline Clock test & II (2.8) & II.2(2.8) & $11.2(2)$ & $10.8(3.5)$ & $10.9(2.9)$ & 0.95 \\
\hline$A D L$ & $5.8(0.5)$ & $5.8(0.4)$ & $5.6(0.8)$ & $5.9(0.2)$ & $5.8(0.4)$ & 0.4 \\
\hline IADL & $7.7(\mathrm{I})$ & $7.4(1.5)$ & $7.6(1)$ & $7.9(0.5)$ & $7.9(0.3)$ & 0.34 \\
\hline GDS & $1.8(2.7)$ & $2(3.6)$ & $2.6(3.2)$ & $\mathrm{I}(\mathrm{I} .7)$ & $1.7(1.6)$ & 0.4 \\
\hline \multicolumn{7}{|l|}{ Blood analysis } \\
\hline WBC count $\left(\times 10^{3} / \mu \mathrm{L}\right)$ & $7.1(1.7)$ & $7.5(1.5)$ & $6.8(1.7)$ & $6.9(1.9)$ & $7(1.5)$ & 0.68 \\
\hline $\mathrm{Hb}(\mathrm{g} / \mathrm{dL})$ & $14.2(\mathrm{I} .4)$ & $13.9(1.9)$ & $14.4(1.4)$ & $14.3(1)$ & $14.3(1.5)$ & 0.81 \\
\hline $\operatorname{ESR}(\mathrm{mm} / \mathrm{h})$ & $25.9(23.7)$ & $35.6(36.1)$ & $22.8(15.9)$ & $20.9(18.7)$ & $25.9(20.9)$ & 0.42 \\
\hline $\mathrm{CRP}(\mathrm{mg} / \mathrm{L})$ & $3.2(5.1)$ & $3.7(4)$ & I.4 (2.4) & $4.9(7.9)$ & $2.3(3.2)$ & 0.32 \\
\hline Creatinine (mg/dL) & $\mathrm{I}(0.3)$ & I.I (0.3) & $0.9(0.3)$ & $0.8(0.2)$ & $0.9(0.3)$ & 0.06 \\
\hline eGFR(CKD-EPI) & $74.2(19.5)$ & $64.2(18)$ & $76.3(21)$ & $80.6(18.3)$ & $74.4(18.9)$ & 0.15 \\
\hline Vitamin D (ng/mL) & $20.9(10.6)$ & $23.9(12.3)$ & $20.5(8.1)$ & $18.8(7.8)$ & $20.5(14)$ & 0.67 \\
\hline Vitamin BI2 (pg/mL) & $368.1(204.7)$ & $338.8(122.2)$ & $272.5(122)$ & $449.1(304)$ & $383.7(150)$ & 0.2 \\
\hline Folic acid $(\mathrm{ng} / \mathrm{mL})$ & $7.5(7.2)$ & $5.5(3.1)$ & $5.7(2.5)$ & $9.9(11.1)$ & $8.3(6.7)$ & 0.38 \\
\hline \multicolumn{7}{|l|}{ Bioimpedance analysis } \\
\hline Total body water $\%$ & $52.1(6)$ & $51.4(6.7)$ & $50.9(5.4)$ & $54.5(6.4)$ & $51.7(5.3)$ & 0.31 \\
\hline Fat mass $\%$ & $30.1(8.4)$ & $32.1(9.3)$ & $32.9(6.4)$ & $25.8(8.8)$ & $29.7(7.3)$ & 0.07 \\
\hline Fat-free mass \% & $69.9(8.4)$ & $67.9(9.3)$ & $67.1(6.4)$ & $74.2(8.8)$ & $70.3(7.3)$ & 0.06 \\
\hline
\end{tabular}

Note: Continuous variables are shown as mean (standard deviation) or median (interquartile range), as appropriate, while categorical variables are shown as $\mathrm{n}$ (\%). Abbreviations: 6MWD, 6-minute walking test distance; ADL, activities of daily living; BODE, body mass index, obstruction, dyspnea and exercise; CIRS, Cumulative Illness Rating Scale; CRP, C-reactive protein; eGFR(CKD-EPI), estimated glomerular filtration rate (Chronic Kidney Disease Epidemiology Collaboration); ESR, erythrocyte sedimentation rate; FEV , forced expiratory volume in the first second; FVC, forced vital capacity; GDS, Geriatric Depression Scale; GOLD, Global Initiative for Chronic Obstructive Lung Disease; Hb, hemoglobin; IADL, instrumental activities of daily living; mMRC, modified Medical Research Council; MMSE, mini-mental state examination; RV, residual volume; TLC, total leukocyte count; WBC, white blood cell. 
Table 2 Cross-validated partial least square discriminant analysis prediction of quartiles of n6MWD (upper) and classes of BODE (bottom)

\begin{tabular}{|c|c|c|c|c|}
\hline \multirow[t]{2}{*}{ Prediction n6MWD } & \multicolumn{4}{|c|}{ Reference n6MWD } \\
\hline & $22-111 \mathrm{~m} / \mathrm{m}^{2}$ & $1 / 2-145 \mathrm{~m} / \mathrm{m}^{2}$ & $146-165 \mathrm{~m} / \mathrm{m}^{2}$ & $166-215 \mathrm{~m} / \mathrm{m}$ \\
\hline $22-111$ & 15 & 0 & I & I \\
\hline $112-145$ & 0 & 13 & 1 & 3 \\
\hline $146-165$ & 0 & 2 & 12 & 1 \\
\hline$>165$ & I & I & 2 & 10 \\
\hline \multicolumn{5}{|c|}{ Accuracy: 0.79 (95\% Cl 0.67-0.88, $P<0.00 \mathrm{I})$. Cohen's kappa: $0.72(95 \% \mathrm{Cl} 0.59-0.85, P<0.00 \mathrm{I})$} \\
\hline \multirow{2}{*}{\multicolumn{2}{|c|}{ Prediction BODE classes }} & \multicolumn{3}{|l|}{ Reference BODE classes } \\
\hline & & Good prognosis (BODE $<3$ ) & & Poor prognosis $(B O D E \geq 3)$ \\
\hline \multicolumn{2}{|l|}{ Good prognosis } & 39 & & 6 \\
\hline \multicolumn{2}{|l|}{ Poor prognosis } & 3 & & 15 \\
\hline
\end{tabular}

Abbreviations: n6MWD, 6-minute walking test distance normalized by squared height; BODE, body mass index, obstruction, dyspnea, and exercise.

$111 \mathrm{~m} / \mathrm{m}^{2}$. After 1 year of follow-up, 35 participants $(55.6 \%)$ were still in GOLD A class, $10(15.8 \%)$ were in GOLD B class, nine (14.3\%) in GOLD C class and nine (14.3\%) in GOLD D class; mean 6MWD was 342.8 (SD: 119) m, and mean n6MWD was 123.9 (SD: 42) $\mathrm{m} / \mathrm{m}^{2}$. Median decline in the $6 \mathrm{MWD}$ over the year was $-23.8 \mathrm{~m}$, and median decline in the n6MWD was $-7.9 \mathrm{~m} / \mathrm{m}^{2}$.

Analyzing the baseline quartiles of n6MWD, we observed a progressive reduction in the mean $\mathrm{FEV}_{1} \%$ (from 77.7 [SD: 9] to 57.9 [SD: 22], ANOVA $P=0.02$ ) and in the mean $\mathrm{pO}_{2}$ (from $84 \mathrm{mmHg}$ [SD: 8.5 ] to $74.4 \mathrm{mmHg}$ [SD: 11.4], ANOVA $P=0.04$ ), as well as a reduction in the mean fatfree mass percent (FFM\%), from the quartile with the highest treaded distance to that with the lowest, and an increase in mMRC score, BODE index and BMI. The PLS-DA based on electronic nose sensors was able to discriminate baseline quartiles of n6MWD, correctly allocating 50 out of 63 patients with an overall accuracy of 0.79 (95\% CI $0.67-0.88$,
$P<0.001)$ and a Cohen's kappa of 0.72 (95\% CI 0.59-0.85, $P<0.001)$. Moreover, 54 patients out of the 63 participants were correctly classified into the baseline classes based on BODE index ("good prognosis" vs "poor prognosis") with an accuracy of 0.86 (95\% CI $0.75-0.93, P<0.001)$, a sensitivity of 0.71 , a specificity of 0.93 and a Cohen's kappa of 0.67 (95\% CI 0.47-0.87, $P<0.001$ ) (Table 2).

GOLD classes did not identify quartiles of n6MWD $\left(\mathrm{m} / \mathrm{m}^{2}\right)$, and we did not find a linear reduction of the walked distance across GOLD classes, obtaining an accuracy in predicting quartiles of walked meters per meter square of 0.35 (95\% CI $0.23-0.48, P=0.05)$ with a poor agreement: Cohen's kappa of 0.14 (95\% CI -0.02 to $0.29, P=0.03)$ (Table 3).

Prediction of the two classes ("stable/improved" vs "worsened") of n6MWD variation based on the electronic nose sensors responses correctly classified 54 out of the 63 COPD patients with an accuracy of 0.86 (95\% CI $0.75-0.93$,

Table 3 Confusion matrix with the distribution per GOLD classes of the n6MWD (top) and classes of BODE (bottom)

\begin{tabular}{|c|c|c|c|c|}
\hline \multirow[t]{2}{*}{ GOLD classes } & \multicolumn{4}{|c|}{ Reference n6MWD } \\
\hline & $22-111 \mathrm{~m} / \mathrm{m}^{2}$ & $1 / 2-145 \mathrm{~m} / \mathrm{m}^{2}$ & $146-165 \mathrm{~m} / \mathrm{m}^{2}$ & $166-215 \mathrm{~m} / \mathrm{m}^{2}$ \\
\hline A & 4 & 9 & 11 & 11 \\
\hline B & 5 & 0 & 2 & 2 \\
\hline$C$ & I & 3 & 2 & 2 \\
\hline$D$ & 6 & 4 & I & 0 \\
\hline \multicolumn{5}{|c|}{ Accuracy: 0.35 (95\% Cl 0.23-0.48, $P=0.05)$. Cohen's kappa: $0.14(95 \% \mathrm{Cl}-0.02$ to $0.29, P=0.03)$} \\
\hline \multirow[t]{2}{*}{ GOLD classes } & & \multicolumn{3}{|l|}{ Reference BODE classes } \\
\hline & & \multicolumn{2}{|l|}{ Good prognosis (BODE $<3$ ) } & Poor prognosis (BODE $\geq 3$ ) \\
\hline $\bar{A}$ & & \multicolumn{2}{|l|}{34} & 1 \\
\hline B & \multicolumn{2}{|r|}{3} & \multicolumn{2}{|r|}{6} \\
\hline C & \multicolumn{2}{|r|}{4} & \multicolumn{2}{|r|}{4} \\
\hline D & \multicolumn{2}{|r|}{ I } & \multicolumn{2}{|r|}{10} \\
\hline
\end{tabular}

Abbreviations: GOLD, Global Initiative for Chronic Obstructive Lung Disease; n6MWD, 6-minute walking test distance normalized by squared height; BODE, body mass index, obstruction, dyspnea, and exercise. 
Table 4 Cross-validated partial least squares discriminant analysis prediction of the n6MWD variation classes over the year of followup based only on BIONOTE (top), only on GOLD classification (center) and on BIONOTE + GOLD classification (bottom)

\begin{tabular}{|c|c|c|}
\hline \multirow{2}{*}{$\begin{array}{l}\text { BIONOTE-based prediction } \\
\text { of } \triangle \text { n6MWD classes }\end{array}$} & \multicolumn{2}{|c|}{ Reference $\triangle \mathrm{n} 6 \mathrm{MWD}$ classes } \\
\hline & Worsened & Stable/improved \\
\hline Worsened & 28 & 5 \\
\hline Stable/improved & 4 & 26 \\
\hline \multicolumn{3}{|c|}{ Accuracy: 0.86 ( $95 \% \mathrm{Cl} 0.75-0.93, P<0.00 \mathrm{I})$. Sensitivity: 0.84; specificity: 0.88 . Cohen's kappa: $0.7 \mathrm{I}(95 \% \mathrm{Cl} 0.54-0.88, P<0.00 \mathrm{I})$} \\
\hline \multirow{2}{*}{$\begin{array}{l}\text { GOLD-based prediction of } \triangle \mathrm{n} 6 \mathrm{MWD} \\
\text { classes }\end{array}$} & \multicolumn{2}{|c|}{ Reference $\triangle$ n6MWD classes } \\
\hline & Worsened & Stable/improved \\
\hline Worsened & 15 & 13 \\
\hline Stable/improved & 17 & 18 \\
\hline \multicolumn{3}{|c|}{ Accuracy: 0.52 ( $95 \% \mathrm{Cl} 0.39-0.65, P=0.45)$. Sensitivity: 0.58 ; specificity: 0.47 . Cohen's kappa: 0.05 ( $95 \% \mathrm{Cl}-0.20$ to $0.29, P=0.35)$} \\
\hline \multirow{2}{*}{$\begin{array}{l}\text { BIONOTE + GOLD-based prediction } \\
\text { of } \triangle \mathrm{n} 6 \mathrm{MWD} \text { classes }\end{array}$} & \multicolumn{2}{|c|}{ Reference $\triangle$ n6MWD classes } \\
\hline & Worsened & Stable/improved \\
\hline Worsened & 25 & 6 \\
\hline Stable/improved & 7 & 25 \\
\hline \multicolumn{3}{|c|}{ Accuracy: 0.79 (95\% Cl 0.67-0.88, $P<0.00 \mathrm{I})$. Sensitivity: $0.8 \mathrm{I}$; specificity: 0.78 . Cohen's kappa: 0.59 ( $95 \% \mathrm{Cl} 0.39$ to $0.79, P<0.00 \mathrm{I})$} \\
\hline
\end{tabular}

Abbreviations: n6MWD, 6-minute walking test distance normalized by squared height; GOLD, Global Initiative for Chronic Obstructive Lung Disease.

$P<0.001)$, a sensitivity of 0.84 and a specificity of 0.88 , while the accuracy obtained using GOLD classes was 0.52 (95\% CI 0.39-0.65, $P=0.45$ ). Applying PLS-DA on GOLD classes and electronic nose responses together, 49 out of 63 patients were correctly classified with an accuracy of 0.79 (95\% CI 0.67-0.88, $P<0.001$ ), a sensitivity 0.81 and a specificity of 0.78. Cohen's kappa was 0.71 (95\% CI 0.54-0.88, $P<0.001)$ for BIONOTE-based prediction, $0.05(95 \%$ $\mathrm{CI}-0.20$ to $0.29, P=0.35)$ for GOLD-based prediction and 0.59 (95\% CI -0.39 to $0.79, P<0.001)$ for the model based on their combination. Data are summarized in Table 4.

\section{Discussion}

Exhaled VOCs analysis using electronic nose discriminates baseline BODE classes and quartiles of n6MWD, and is able to predict n6MWD variation over 1 year of follow up, better than the GOLD classes.

Our data show that inclusion of dyspnea and exacerbation rate notwithstanding, the problem of GOLD classification may be that it remains mainly focused on respiratory parameters, ignoring that COPD is a disease with important systemic impact. Indeed, risk factors of COPD, that is, cigarette smoking, induce systemic inflammation and oxidative stress, ${ }^{32}$ as well as changes in endothelial function favoring a prothrombotic state, ${ }^{33}$ resulting in a higher prevalence of chronic comorbidities (eg, heart failure, pulmonary vascular diseases, etc). ${ }^{34}$ Thus, COPD is seldom an isolated disorder, and usually comorbidity impacts health outcomes, particularly survival, in COPD patients. Indeed, COPD exacerbation leading to respiratory failure accounts only for $35 \%$ of COPD patients' death. ${ }^{35}$ This evidence fosters the use of VOCs analysis. VOCs are low-weight molecules produced by cellular metabolism; therefore, bacterial infections, metabolic abnormalities, toxic ingestion, chronic diseases (eg, heart failure, liver cirrhosis) and cancer produce a qualitative and quantitative change in their production. ${ }^{17}$ Hence, although COPD induces its particular change in exhaled VOCs, useful in the diagnosis of the disorder, patient's breathprint is the end result of the overall cellular metabolism disarray, also caused by comorbidities. ${ }^{36}$ Indeed, analyzing the characteristics of patients divided per quartiles of n6MWD, we observed that VOCs are not just influenced by airflow limitation and dyspnea, also captured by GOLD classification, but besides they take into account body composition, as described by a statistically significant increase in BMI associated with a reduction in FFM\%, a well-demonstrated factor affecting COPD functional status. ${ }^{37}$ Furthermore, they are not affected by the number of exacerbations per year, which, although improving ability to predict hospital admission due to COPD exacerbation, ${ }^{4}$ do not seem to be correlated with functional status. This is a possible explanation of why the model based on VOCs was able to discriminate better than GOLD classes both 6MWD and BODE index as well as to identify, in the longitudinal analysis, a worsening of patients' functional status.

Moreover, our results confirm the known limitations of the 2014 GOLD classification in the identification of COPD functional status. This new classification, despite considering dyspnea and exacerbation, did not outperform the 2007 GOLD classification based only on airflow limitation, ${ }^{4,6}$ and it is characterized by a poor ability in COPD functional status 
stratification: subgroup B has a poorer survival and a higher rate of hospital admission than subgroup $\mathrm{C}^{4,5}$ and is characterized by a lower 6MWD and a higher BODE index than subgroup C. ${ }^{38}$ In our analysis, GOLD classification showed a poor agreement both with baseline quartiles of n6MWD and classes of BODE and with longitudinal variation of n6MWD, as demonstrated by Cohen's kappa, significantly lower than that obtained by VOCs analysis. Furthermore, we observed that while GOLD A is clearly composed of subjects with a good functional status, and GOLD D of subjects with the worst, GOLD B and GOLD C have subjects with intermediate impairment and are rather similar, with GOLD B being slightly worse; hence, there is no linear progression of impairment confirming reports of previous studies. ${ }^{38}$

\section{Strengths and limitations}

This study has some limitations. Firstly, using an electronic nose technology, we could not identify single components of exhaled breath, as is possible with other techniques (eg, gas chromatography-mass spectrometry). However, the purpose of this study was to develop a simple and inexpensive metabolic marker: electronic nose analysis costs are about $€ 10$, whereas analytic methods of breath samples are costly and not suitable for routine clinical use, and comparable, or even cheaper, than that of 6MWT (about $€ 50$ ). Secondly, VOCs may be influenced by room conditions, smoke, drugs and food, but we minimized the potential bias of these factors, asking patients not to smoke, eat, or drink and not to consume medication for at least 8 hours, and performing collection always in the same room. Furthermore, to date, there does not exist an electronic nose considered as the "gold standard" in VOCs analysis; thus, BIONOTE has never been compared with other electronic nose devices. Finally, we acknowledge that the choice to normalize 6MWD per patients' squared height to minimize the impact of anthropometric features is arbitrary, although conventionally used.

The study also has some strengths. We performed a multidimensional assessment of the whole population, not limited to respiratory parameters. Furthermore, the longitudinal design of the study allowed us to analyze the correlation between exhaled VOCs analysis and the variation of the 6MWD.

\section{Conclusion}

Exhaled VOCs analysis using electronic nose may be used for a better characterization of COPD patients' functional status. Considering that exhaled breath collection and analysis has a very low cost, does not require a long and straight corridor and is suitable for all patients, even for those who are unable to perform a 6MWT or a spirometry, it represents a promising technique in the COPD functional status assessment.

\section{Acknowledgments}

The authors would like to thank Dr Federica Sabato, Dr Veronica Adiletta and Dr Leonardo Grisafi for their help in data collection. This study was funded by an unrestricted grant from Fondazione Roma, Italy.

\section{Author contributions}

$\mathrm{PF}, \mathrm{CP}$ and RAI participated in planning the study. PF and $\mathrm{CP}$ performed data analyses. All authors participated in data collection, revised the final version of the manuscript and gave their consent to publication.

\section{Disclosure}

The authors GP, MS and RAI are holders of the Pneumopipe ${ }^{\circledR}$ patent. The other authors report no conflicts of interests in this work.

\section{References}

1. Burney PGJ, Patel J, Newson R, Minelli C, Naghavi M. Global and regional trends in COPD mortality, 1990-2010. Eur Respir J. 2015;45(5):1239-1247.

2. Gold PM. The 2007 GOLD guidelines: a comprehensive care framework. Respir Care. 2009;54(8):1040-1049.

3. Vestbo J, Hurd SS, Agustí AG, et al. Global strategy for the diagnosis, management, and prevention of chronic obstructive pulmonary disease: GOLD executive summary. Am J Respir Crit Care Med. 2013;187(4):347-365.

4. Lange P, Marott JL, Vestbo J, et al. Prediction of the clinical course of chronic obstructive pulmonary disease, using the new GOLD classification: a study of the general population. Am J Respir Crit Care Med. 2012;186(10):975-981.

5. Goossens LMA, Leimer I, Metzdorf N, Becker K, Rutten-van Mölken MPH. Does the 2013 GOLD classification improve the ability to predict lung function decline, exacerbations and mortality: a post-hoc analysis of the 4-year UPLIFT trial. BMC Pulm Med. 2014;14:163.

6. Soriano JB, Lamprecht B, Ramírez AS, et al. Mortality prediction in chronic obstructive pulmonary disease comparing the GOLD 2007 and 2011 staging systems: a pooled analysis of individual patient data. Lancet Respir Med. 2015;3(6):443-450.

7. Durheim MT, Smith PJ, Babyak MA, et al. Six-minute-walk distance and accelerometry predict outcomes in chronic obstructive pulmonary disease independent of Global Initiative for Chronic Obstructive Lung Disease 2011 Group. Ann Am Thorac Soc. 2015;12(3):349-356.

8. Cote CG, Pinto-Plata V, Kasprzyk K, Dordelly LJ, Celli BR. The 6-min walk distance, peak oxygen uptake, and mortality in COPD. Chest. 2007;132(6): 1778-1785.

9. Casanova C, Cote C, Marin JM, et al. Distance and oxygen desaturation during the 6-min walk test as predictors of long-term mortality in patients with COPD. Chest. 2008;134(4):746-752.

10. Celli BR, Cote CG, Marin JM, et al. The body-mass index, airflow obstruction, dyspnea, and exercise capacity index in chronic obstructive pulmonary disease. N Engl J Med. 2004;350(10):1005-1012.

11. ATS Committee on Proficiency Standards for Clinical Pulmonary Function Laboratories. ATS statement: guidelines for the six-minute walk test. Am J Respir Crit Care Med. 2002;166(1):111-117. 
12. Fens N, Zwinderman AH, van der Schee MP, et al. Exhaled breath profiling enables discrimination of chronic obstructive pulmonary disease and asthma. Am J Respir Crit Care Med. 2009;180(11): 1076-1082.

13. Finamore P, Pedone C, Lelli D, et al. Analysis of volatile organic compounds: an innovative approach to heart failure characterization in older patients. $J$ Breath Res. 2018;12(2):026007.

14. Fens N, de Nijs SB, Peters S, et al. Exhaled air molecular profiling in relation to inflammatory subtype and activity in COPD. Eur Respir J. 2011;38(6):1301-1309.

15. Finamore P, Scarlata S, Santangelo S, et al. Clustering Approach and Effects of Inhaled Therapy on Breath-Fingerprint of Newly Diagnosed COPD Patients: An e-Nose Based Study. Eur Respiratory Soc. 2017; 50 Suppl 61.

16. Garcia-Aymerich J, Serra I, Gómez FP, et al. Physical activity and clinical and functional status in COPD. Chest. 2009;136(1):62-70.

17. Shirasu M, Touhara K. The scent of disease: volatile organic compounds of the human body related to disease and disorder. J Biochem (Tokyo). 2011;150(3):257-266.

18. Miller MR, Hankinson J, Brusasco V, et al. Standardisation of spirometry. Eur Respir J. 2005;26(2):319-338.

19. Wanger J, Clausen JL, Coates A, et al. Standardisation of the measurement of lung volumes. Eur Respir J. 2005;26(3):511-522.

20. Katz Index of Independence in Activities of Daily Living. Geriatr Nurs (Lond). 2000;21(2):109.

21. Graf C. The Lawton Instrumental Activities of Daily Living (IADL) Scale. ConsultGeri. Available from: https://consultgeri.org/try-this/ general-assessment/issue-23. Accessed October 25, 2017.

22. Tombaugh TN, McIntyre NJ. The mini-mental state examination: a comprehensive review. J Am Geriatr Soc. 1992;40(9):922-935.

23. D'Ath P, Katona P, Mullan E, Evans S, Katona C. Screening, detection and management of depression in elderly primary care attenders. I: The acceptability and performance of the 15 item Geriatric Depression Scale (GDS15) and the development of short versions. Fam Pract. 1994;11(3):260-266.

24. Horváth I, Barnes PJ, Loukides S, et al. A European Respiratory Society technical standard: exhaled biomarkers in lung disease. Eur Respir J. 2017;49(4).

25. D'Amico A, Di Natale C, Paolesse R, et al. Olfactory systems for medical applications. Sens Actuators B Chem. 2008;130(1):458-465.
26. Casanova C, Celli BR, Barria P, et al. The 6-min walk distance in healthy subjects: reference standards from seven countries. Eur Respir J. 2011;37(1):150-156.

27. Porteous MK, Rivera-Lebron BN, Kreider M, Lee J, Kawut SM. Determinants of 6-minute walk distance in patients with idiopathic pulmonary fibrosis undergoing lung transplant evaluation. Pulm Circ. 2016;6(1):30-36.

28. Uszko-Lencer NHMK, Mesquita R, Janssen E, et al. Reliability, construct validity and determinants of 6-minute walk test performance in patients with chronic heart failure. Int J Cardiol. 2017;240:285-290.

29. Miller MR, Pedersen OF. New concepts for expressing forced expiratory volume in $1 \mathrm{~s}$ arising from survival analysis. Eur Respir J. 2010;35(4):873-882.

30. Andrianopoulos V, Wouters EFM, Pinto-Plata VM, et al. Prognostic value of variables derived from the six-minute walk test in patients with COPD: results from the ECLIPSE study. Respir Med. 2015;109(9):1138-1146.

31. Kwiecien R, Kopp-Schneider A, Blettner M. Concordance analysis. Dtsch Ärztebl Int. 2011;108(30):515-521.

32. MacNee W. Pulmonary and systemic oxidant/antioxidant imbalance in chronic obstructive pulmonary disease. Proc Am Thorac Soc. 2005;2(1):50-60

33. MacCallum PK. Markers of hemostasis and systemic inflammation in heart disease and atherosclerosis in smokers. Proc Am Thorac Soc. 2005;2(1):34-43.

34. Clini EM, Beghé B, Fabbri LM. Chronic obstructive pulmonary disease is just one component of the complex multimorbidities in patients with COPD. Am J Respir Crit Care Med. 2013;187(7):668-671.

35. Hansell AL, Walk JA, Soriano JB. What do chronic obstructive pulmonary disease patients die from? A multiple cause coding analysis. Eur Respir J. 2003;22(5):809-814.

36. Antonelli Incalzi R, Pennazza G, Scarlata S, et al. Comorbidity modulates non invasive ventilation-induced changes in breath print of obstructive sleep apnea syndrome patients. Sleep Breath. 2015;19(2):623-630.

37. Tsiligianni I, Kocks J, Tzanakis N, Siafakas N, van der Molen T. Factors that influence disease-specific quality of life or health status in patients with COPD: a review and meta-analysis of Pearson correlations. Prim Care Respir J. 2011;20(3):257-268.

38. Agusti A, Edwards LD, Celli B, et al. Characteristics, stability and outcomes of the 2011 GOLD COPD groups in the ECLIPSE cohort. Eur Respir J. 2013;42(3):636-646.
International Journal of COPD

\section{Publish your work in this journal}

The International Journal of COPD is an international, peer-reviewed journal of therapeutics and pharmacology focusing on concise rapid reporting of clinical studies and reviews in COPD. Special focus is given to the pathophysiological processes underlying the disease, intervention programs, patient focused education, and self management protocols.

\section{Dovepress}

This journal is indexed on PubMed Central, MedLine and CAS. The manuscript management system is completely online and includes a very quick and fair peer-review system, which is all easy to use. Visit http://www.dovepress.com/testimonials.php to read real quotes from published authors. 